\title{
De Mary Richmond a Karl R. Popper y Emmanuel Lévinas: hacia la cientificidad y el conocimiento ético para el Trabajo Social
}

\author{
From M. Richmond to K. R. Popper and E. Lévinas: \\ toward a scientific approach and ethical knowledge for Social Work
}

\author{
Francisco IDARETA GoldARACENA \\ Universidad Pública de Navarra \\ fran_idareta@yahoo.es
}

Recibido: 19/05/2011

Revisado: 27/05/2011

Aceptado: 27/06/2011

Disponible on line: 29/09/2011

\begin{abstract}
Resumen
Cuando nos encontramos en pleno debate sobre la cientificidad o no de una disciplina teórico-práctica como el Trabajo Social, este artículo pretende presentar de modo sucinto dos alternativas por las que el Trabajo Social podría adquirir rango científico a la par que un conocimiento ético. Nuestra opinión es que la única teoría específica de Trabajo Social es la propuesta por M.E. Richmond. Una propuesta que, desde el punto de vista de K.R. Popper, no deja de ser pseudocientífica por ser inductivista y desde el punto de vista de E. Lévinas ontológica y tendente a categorizar definitivamente al Otro. Por todo ello, el objetivo de este artículo consiste en analizar tanto las propuestas de Popper y Lévinas para aproximarlas al Trabajo Social como alternativas ético-científicas a la propuesta inductivista y categorizante de Richmond, utilizando para ello una metodología histórico-sistemática, consistente en analizar las obras más importantes de estos autores así como de la ética de la intervención social.
\end{abstract}

Palabras clave: epistemología, ética, Trabajo Social, intervención Social, M.E. Richmond, K. R. Popper, E. Lévinas.

\begin{abstract}
As we find ourselves in the midst of a debate regarding the scientific nature or the lack thereof of theoretical-practical disciplines such as Social Work, this article aims to succinctly present two alternatives by which Social Work may obtain a scientific rank on par with ethical knowledge. Our opinion is that the only theory specific to Social Work is the one proposed by M. E. Richmond. A proposal that, from K. R. Popper's point of view, is still pseudoscientific given its inductive nature, and from the point of view of E. Lévinas, is ontological and tends to definitively categorize the Other. The objective of this article, therefore, is to analyze Popper's as well as Lévinas' proposals in order to provide an approach to Social Work with ethical-scientific alternatives to the inductive and categorizing proposal put forward by Richmond, using a historical-systematic methodology which consists of analyzing the most important works of these authors as well as the ethics of social intervention.
\end{abstract}

Keywords: epistemology, ethics, social work, social intervention, M. E. Richmond, K. R. Popper, E. Lévinas.

Referencia normalizada: Idareta Goldaracena, F. (2011). «De Mary Richmond a Karl R. Popper y Emmanuel Lévinas: hacia la cientificidad y el conocimiento ético para el Trabajo Social». Cuadernos de Trabajo Social, 24: 85-99.

Sumario: Introducción. 1. Trabajo Social ¿científico? 2. Crítica y autocrítica en Trabajo Social como pieza clave para su eticidad y cientificidad. 3. El inductivismo. Establecimiento de las bases epistemológicas del Trabajo Social por Mary Ellen Richmond. 4. El racionalismo crítico. Aproximación a la epistemología de Karl R. Pepper al Trabajo Social. 5. Ética del rostro. Aproximación a la ética de E. Lévinas al Trabajo Social. 6. Conclusiones. 7. Referencias bibliográficas.

La tarea del científico no es descubrir la certeza absoluta, sino descubrir teorías cada vez mejores (...) capaces de someterse a contrastaciones cada vez más rigurosas. (...) La ciencia progresa mediante su falsación (Popper, 2010, p. 423).

La ética no se deriva de una ontología de la naturaleza; es lo opuesto a ésta, una "meontología» que afirma que hay sentido más allá del ser, un modo primero de no-ser (Lévinas y Kearney, 1998, p. 209). 


\section{Introducción}

El Trabajo Social es una disciplina teóricopráctica que surge en Inglaterra a mediados del siglo XIX, vinculada a las organizaciones sociales de caridad. Las organizaciones privadas de esta época se hacían cargo de la pobreza de modo irreflexivo, descoordinado y desorganizado, promoviendo la caridad perniciosa, es decir, la donación de limosna de forma indiscriminada, favoreciendo de ese modo la dependencia, el derroche, la ociosidad de los beneficiarios de la ayuda y la degeneración de su carácter, así como el incremento desproporcionado de su pobreza. Frente a este proceder, las organizaciones sociales de caridad pretenden, de modo reflexivo, coordinado y organizado, promover la autoayuda, erradicando para ello esta caridad perniciosa. Pretenden, por una parte, reducir la pobreza promoviendo el trabajo como medio para ganar dinero y, por otra, generar la independencia del sujeto, así como su contención y autocontrol económico. Todo ello, moralizando a sus proto-usuarios (Moix, 2006, pp. 73-89). Es así como en 1869 surge en Inglaterra el proto-Trabajo Social, que se caracteriza por la ayuda social que ofrece, así como por el voluntariado y la pre-profesionalización de su actividad. En 1877, Josephine Shaw Lowell exporta este proto-Trabajo Social a EE.UU. Allí Mary Richmond sienta las bases epistemológicas del Trabajo Social a partir de este proto-Trabajo Social.

Desde su fundación, el Trabajo Social se ha mostrado siempre muy preocupado por cuestiones ético-epistemológicas y, como disciplina ${ }^{1}$ teórica que surge en este contexto histórico determinado, posee la impronta de lo que por aquel entonces se consideraba ciencia. Si partimos de reconocer que el diagnóstico social propuesto por Richmond uti- liza el método inductivo, algo que se traslada en su lema saber para actuar, no es de extrañar que esta autora no nos instara a evaluar nuestra intervención. Según esta autora, el/la trabajador/a social observa la realidad a través de los sentidos y, libre de prejuicios, es como capta la verdad definitiva, infalible, perfecta. Así, y sólo así, se encuentra en condiciones de intervenir con el usuario. El conocimiento teórico adquirido de ese modo por el profesional era considerado científico en aquella época y se encontraba justificado porque el resto de profesiones afines, entre las que destacaba la Medicina, así lo venían considerando. De alguna manera, encontramos sentido a que el conocimiento teórico derivado del método inductivo fuera considerado científico en aquella época, en aquel contexto histórico.

Lo que nos resulta curioso es que, especialmente durante el siglo XX, mientras que el resto de profesiones afines (Sociología, Psicología, etc.) han asistido a una profunda revisión de sus bases epistemológicas, el Trabajo Social se ha limitado a rescatar teorías de otras disciplinas para poder aplicarlas a la intervención social. El Trabajo Social, por los motivos que fuesen, en vez de producir teoría específica de Trabajo Social, como otras disciplinas de su generación, ante la ausencia de teorías específicas del campo que consiguieran explicar la realidad social de sus usuarios, se lanza a la búsqueda y captura de teorías de otras disciplinas para aplicarlas a la intervención social. El Trabajo Social prefiere hacer uso de éstas antes que producir la suya propia. Por otra parte, como veníamos anticipando, en la propuesta epistemológica de Richmond no se contemplaba la evaluación. Lo importante era únicamente saber (conocer al usuario mediante el diagnóstico social que utilizaba la

\footnotetext{
${ }^{1}$ En la actualidad, pese a que en España el Consejo de Universidades contempla el Trabajo Social como Área de Conocimiento (Trabajo Social y Servicios Sociales: 813), no está contemplado como tal ni por la UNESCO ni como área de conocimiento. Véase el siguiente enlace actualizado el 16 de Febrero de 2011: http://www.et.bs.ehu.es/varios/unesco.htm. No obstante, si hemos de ser rigurosos, el Trabajo Social debería ser contemplado como Campo (representado con dos dígitos) y sus diferentes especialidades como Disciplinas (representadas con cuatro dígitos). Urge que los profesionales del Trabajo Social hagamos entre tanto lo que esté en nuestras manos para que nuestra disciplina adquiera el rango de ciencia. Sirva por ello este artículo como excusa para prolongar la discusión crítica que se pueda estar produciendo sobre esta cuestión de vital trascendencia para nuestra profesión.
} 
inferencia inductiva) y actuar (intervenir en base a este conocimiento infalible, perfecto del usuario). Efectivamente, dado que la evaluación no había sido integrada en el corpus teórico del Trabajo Social, conjeturamos que podría haber derivado en una generalizada actitud acrítica de los profesionales que únicamente se limitaban a aplicar teorías de otras disciplinas sin cuestionarse ni preocuparse por la teoría específica de Trabajo Social que podría extraerse de tal aplicación.

\section{Trabajo Social ¿científico?}

Nos encontramos en pleno siglo XXI y el Trabajo Social, tras siglo y medio de andadura, continúa sin concienciarse de la importancia de producir teorías específicas propias de la disciplina: teorías científicas y éticas propias. A lo largo del siglo pasado proliferaron los modelos de intervención de Trabajo Social (Viscarret, 2007), haciendo creer a propios y a extraños que aquello era teoría específica de Trabajo Social. Bajo nuestro punto de vista, nada más lejos de la realidad. Para que una teoría sea propia del Trabajo Social debe tener como objeto de su crítica otra teoría específica suya o, si es una teoría de disciplinas afines, la experiencia práctica de Trabajo Social que de ella se derive. Nuestra hipótesis es que, el hecho de que Richmond, preocupada por la urgencia de utilizar el método inductivo, probablemente en boga en su época y empleado por la Medicina, no contemplase por ello la importancia de la evaluación, nos ha llevado a los profesionales del campo a mantenernos tradicionalmente bastante (más bien, demasiado) acríticos ante nuestro conocimiento y nuestras intervenciones, así como poco sensibilizados y motivados para la producción del conocimiento científico propio de la disciplina.

Pensamos que la propuesta de Richmond ha impulsado a los profesionales, entre otras cuestiones, a estar pendientes de valorar si el usuario es o no merecedor de ayuda, así como a administrar aquellos recursos que éste pueda necesitar, sin instarles a preocuparse por cuestionarse la teoría en base a la cual actúan y qué podría aportar su intervención a esta u otra teoría. La propuesta de Richmond nos ha llevado a saber para actuar, haciendo que los profesionales, absortos en todas estas cuestiones, no consiguieran llegar a plantearse que de estas teorías de disciplinas afines es posible extraer teoría específica del Trabajo Social: craso error por el que la profesión está pagando muy caro y del que todos y cada uno de los profesionales debemos sentirnos responsables. La base epistemológica inductivista establecida por Richmond nos ha llevado a los profesionales del campo a estar pendientes únicamente de adquirir los conocimientos necesarios (aunque no los suficientes, por los contextos burocratizados en los que muchas y muchos colegas trabajan) para poder dar respuesta a los requerimientos más o menos inmediatos de nuestros usuarios. Este trasfondo epistemológico permanece vigente en la actualidad. Su fantasma merodea como alma errante sin poder acceder al descanso eterno, mientras no osemos plantear nuevas alternativas.

A todo lo anterior hay que añadir que, de un tiempo a esta parte, la literatura especializada viene insistiendo en la cientificidad del Trabajo Social (Fernández y López, 2008, pp. 12, 47 y ss., 89; Fernández y Ponce, 2008, p. 34; Ponce y Fernández, 2009, pp. 261 y ss.; López, 2010, pp. 37 y ss.). Algo frente a lo que no podemos dejar de plantearnos la siguiente cuestión: ¿qué hace que el Trabajo Social sea científico? Los autores de las obras en las que se señala que el Trabajo Social es una disciplina científica argumentan que lo es si se aplica el método científico. Dudamos que sean muchos los profesionales del Trabajo Social que sepan con exactitud en qué consiste el método científico, y muchos menos quienes lo practiquen y sepan que, lejos de reduccionismos, el método científico sobre todo es una actitud crítica sistemática, constante y consciente, y no un mero instrumento cuya mecánica aplicación origina teorías perfectas.

Si el Trabajo Social fuera científico, es decir, si utilizara el método científico, el método crítico, consideramos que las contribuciones teórico-prácticas existentes (en relación a otras disciplinas afines que surgieron a la par que el Trabajo Social como la Sociología, la Psicología, etc.) no serían tan escasas como en la actualidad (aunque tengamos el privilegio de asistir a un sustancial resurgimiento de nuevas y esperanzadoras publicaciones 
en los últimos años). Si cada profesional fuera consciente de que su profesión debe ser ejercida manteniendo una actitud crítica y autocrítica para con sus conocimientos y su intervención, este resurgimiento se habría producido muchísimo antes. Pero éste no justifica en absoluto que podamos denominar científico al Trabajo Social. Rango que, a nuestro modo de ver, todavía no ha alcanzado y que, de seguir en la misma línea, tardará años en lograr.

Creemos que lo que a Richmond le faltó por inocular al Trabajo Social fue precisamente la actitud crítica y autocrítica constante, la urgencia de la evaluación de cuanto conozcamos y hagamos en el ejercicio de nuestra profesión. Pero Richmond era hija de su tiempo: por ello sentó las bases epistemológicas de nuestra profesión inspirándose en lo que entonces se consideraba científico. Su encomiable labor fundacional nunca se la podremos agradecer lo suficiente. Así, lejos de pretender culpabilizar a nuestra admirada fundadora, lo que pretendemos, siendo coherentes y consecuentes con nuestra propuesta, es hacer autocrítica de tantos y tantos años sin producir teoría específica de Trabajo Social. Dado que las teorías de otras disciplinas conseguían compensar nuestra falta de producción teórica y explicaban y planteaban soluciones a los problemas de nuestros usuarios, los profesionales nos hemos venido autoengañando. Hemos creído que los modelos de intervención social son teoría específica de Trabajo Social, pero no es así.

Por ello nuestra propuesta apunta en la siguiente dirección: sólo la utilización de la actitud crítica y autocrítica en la aplicación de teorías de las diferentes disciplinas afines puede dar lugar a teorías específicas de Trabajo Social. Sólo la evaluación de nuestra experiencia en la aplicación de los distintos modelos de Trabajo Social podrá originar teoría específica, científica y ética de Trabajo Social (Vázquez, 2008, pp. 227, 229, 236-237). Las/los trabajadoras/es sociales comenzamos a ser conscientes de que la práctica la llevamos a cabo a partir de una o varias teorías. En definitiva, siguiendo a Popper, comenzamos a caer en la cuenta de que observamos diferentes aspectos de la realidad, debido a que una determinada teoría que precede a dicha observación, nos orienta a ello (Popper, 2010, pp. 401, 405; Popper, 1997, pp. 28, 177, 195; Popper, 2003, pp. 234, 237, 302). Por tanto, comenzamos a ser conscientes de que la práctica adquiere sentido a la luz de la teoría. Pero todavía no hemos caído en la cuenta suficientemente de que de tal práctica se puede extraer, precisamente con este método científico, teoría específica del Trabajo Social. No nos hemos concienciado lo suficiente de la necesidad de realizar de forma sistemática la evaluación en Trabajo Social (Vázquez, 2008).

\section{Crítica y autocrítica en Trabajo Social como pieza clave para su eticidad y cienti- ficidad}

Como anticipábamos, en la literatura de Trabajo Social se ha comenzado a aludir a que esta disciplina es científica, incorporando la evaluación como actividad imprescindible a realizar. De hecho, consideramos que, efectivamente, la cientificidad del Trabajo Social viene de la mano de esta actitud crítica y autocrítica que el profesional mantiene cuando realiza la evaluación del usuario y sus circunstancias, de los conocimientos que tiene del mismo, así como de los objetivos, metodología, calendarización y recursos de su intervención (Vázquez, 2008). Pero, en nuestra opinión, si la única teoría de Trabajo Social era la de Richmond -es decir, el diagnóstico social-y éste no contemplaba la evaluación, ¿quién, cómo y cuándo ha sido añadida esta fase al Trabajo Social? El propósito perseguido nos lo podemos imaginar: hacer del Trabajo Social una disciplina teórico-práctica científica. Pero quienes hayan llevado a cabo esta añadidura, deberían justificar la inclusión de esta fase, tan importante para el Trabajo Social, no poniendo simplemente el calificativo de científico sino realizando una pertinente crítica de la propuesta richmoniana. No se puede añadir el método crítico al método inductivo y permanecer impasibles ante ello. No se puede mezclar ambos métodos. El conocimiento que extrae el uno es seguro y definitivo, mientras que el que extrae el otro es inseguro y provisional.

Creemos que no basta con agregar de modo acrítico y sin ninguna explicación la evaluación a las fases señaladas por Richmond 
(saber e intervenir) ${ }^{2}$. Sobre todo porque, según Richmond, el conocimiento teórico que adquiría el profesional era un conocimiento infalible, perfecto para, seguidamente, intervenir con el usuario. Este conocimiento es incompatible con la consideración actual de conocimiento científico. La inclusión de la fase de evaluación requiere por tanto una explicación del proceso transitorio entre el conocimiento teórico derivado del método inductivo y el que deriva del método científico o hipotético deductivo, consistente en la actitud crítica y autocrítica con nuestro conocimiento y nuestra intervención. No es suficiente con agregar el método crítico, propio del método hipotético deductivo, a las fases de diagnóstico social y de intervención, propias del método inductivo richmoniano.

Para Richmond, su propuesta no estaba tan incompleta como para justificar la posterior incorporación de la fase de evaluación a su método. Somos nosotros, conscientes de lo que en la actualidad es ciencia, quienes debemos hacer una crítica, no ya de lo incompleto, sino de lo pseudocientífico de esta propuesta que, dicho sea de paso, cuenta ya más de un siglo. Desde nuestro punto de vista, el Trabajo Social no adquirirá rango científico más que cuando los profesionales de este campo se convenzan de la importancia de mantener una actitud crítica y autocrítica constante, sistemática y consciente para la adquisición de un conocimiento científico que, sólo siéndolo, será también ético.

La explicación de este proceso transitorio entre el inductivismo de Richmond y el actualmente preconizado método ético-científico la encontramos en las propuestas de autores como Emmanuel Lévinas y Karl R. Popper. Mientras que Lévinas ha profundizado mucho más en su propuesta ética, Popper lo ha hecho en su planteamiento epistemológico. No obstante, ambos han planteado unas propuestas ético-epistemológicas sin precedentes, originales y novedosas. Además, tras analizar de manera pormenorizada las obras más importantes de ambos, hemos detectado una posible complementación entre la ética de Lévinas y la epistemología de Popper. Compartimos la tesis de Mariano Artigas (2001), quien señala que la epistemología de Popper es consecuencia -y no causa- de su ética. Algo que lo acerca sorprendentemente a Lévinas, para quien el saber ontológico se encontraba al auspicio de la ética. Del mismo modo, como veremos a continuación, la vida de cada uno influyó sustancialmente en el devenir de sus obras.

Por todo lo anteriormente expuesto, vamos a tratar ahora de explicar los motivos que consideramos deben llevar a los trabajadores sociales a utilizar el método ético-científico desde el punto de vista de Lévinas y Popper para superar el inductivismo del diagnóstico social de Richmond. Expondremos las propuestas de Richmond, Popper y Lévinas, los motivos por los cuales los dos últimos proponen tales alternativas, así como la aproximación de las mismas que le planteamos al Trabajo Social: el humanismo del Otro frente al humanismo clásico en el caso de Lévinas y el racionalismo crítico frente al esencialismo, inductivismo, etc. en el caso de Popper. Finalmente, señalaremos nuestras conclusiones.

\section{El inductivismo. Establecimiento de las bases epistemológicas del Trabajo Social por Mary Ellen Richmond}

Mary Ellen Richmond comienza su andadura profesional trabajando primero como tesorera auxiliar (1889) y posteriormente como secretaria general (1891) en la Organización Social de Caridad de Baltimore. La impronta que dejara en ella Josephine Shaw Lowell -responsable de exportar a EE.UU. el modelo inglés de las Organizaciones Sociales de Caridad (Miranda, 2004, p. 138) y a la que leyera en su primera etapa como visitadora amistosa- fue muy importante. Para Shaw Lowell, lo importante era la relación que se establecía con el necesitado, con el objetivo de conocer su situación para poder actuar en la dirección adecuada en la socialización del sujeto. He aquí los orígenes del lema saber

2 En la actualidad se reconocen las siguientes fases: acogida de información, recopilación de información, elaboración de un diagnóstico, diseño y plan de intervención, aplicación del diseño de intervención y evaluación. Cfr. Ponce y Fernández, 2009, p. 263. 
para actuar que se deduce de la propuesta epistemológica de Richmond ${ }^{3}$. Según Shaw Lowell, de intervenir habría que hacerlo sin perjudicar al sujeto o, de lo contrario, lo mejor sería abandonarlo «a la dura acción de las leyes naturales» (Shaw Lowell, citado en Moix, 2006, p. 130). Su aportación se centró en establecer los criterios de elegibilidad del sujeto merecedor de ayuda (op. cit.).

Así, Richmond se inició en el estudio de la teoría del Trabajo Social con la pretensión de mejorar en lo posible la intervención social. El conocimiento de cada caso resultó fundamental para la planificación de la acción social, motivo por el cual comenzó profundizando en autores de vanguardia de las incipientes disciplinas (Sociología, Psicología...) para fundamentar el corpus teórico del Trabajo Social. Para poder actuar convenientemente hay que comprender al sujeto y su familia -aunque con posterioridad se considerara también imprescindible conocer el contexto general (laboral, residencial, etc.). Sus dos obras fundamentales son Diagnóstico social (1917) y Caso social individual (1922). En cada una se recoge la concepción de Richmond de que la pobreza tiene su origen en el individuo al que va orientado su tratamiento individualizado, así como su utilización de la inferencia inductiva (p. 130). Caso social individual es la obra en la que Richmond desarrolla el método del trabajo social de caso, donde son destacables la comprensión y la acción como pilares fundamentales del mismo, es decir, saber para actuar.

De todo lo anteriormente señalado, pretendemos destacar la inferencia inductiva utilizada por Richmond. La aplicación de generalidades adquiridas en el estudio de casos conocidos a particularidades desconocidas se plasma en Diagnóstico social, cuando, partiendo del estudio pormenorizado de casos individuales llega a inferir conceptos generales aplicables a futuros casos desconocidos. $\mathrm{Pa}-$ ra Richmond, la inferencia, que consiste en «pasar de hechos conocidos a desconocidos, equivale a un proceso de razonamiento», lo que significa que se explicita también el abordaje racionalista sobre el que sustenta su categorización diagnóstica, cuando alude a continuación a que la inferencia «también puede consistir en el establecimiento de una regla general a partir de muchos casos particulares, así como de un nuevo hecho sobre un caso particular a partir de una regla general» (Richmond, 2007, p. 73).

De hecho, para la autora el diagnóstico social consiste en «una definición lo más exacta posible de la situación social y la personalidad de un cliente dado» (p. 35). A través del diagnóstico social adquirimos un conocimiento infalible, perfecto sobre el usuario. Así Richmond parte de una verdad general para poder realizar la inferencia; es decir, parte de inferir reglas generales e impersonales de múltiples casos concretos y personales (Richmond, 2007, pp. 93, 90 y 94 respectivamente). Por otra parte, la autora intenta respaldar tal abordaje racionalista «en relación con las inferencias» (p. 33), empleando para ello libros de lógica. A todo lo anterior hay que añadir que Richmond es consciente de los peligros de categorizar, del riesgo que entrañan tanto las presunciones sin pruebas suficientes como los prejuicios del profesional (Soydan, 2004, pp. 137 138). Por este motivo, para la realización del diagnóstico social Richmond destacaba la importancia de liberarnos de nuestros prejuicios para, sólo así, poder captar el conocimiento puro, así como la importancia de las evidencias o enunciados observacionales a partir de los cuales poder verificar nuestras teorías.

En definitiva, Richmond plantea, como deber del trabajador social, establecer conceptos teóricos generales a partir del conocimiento extraído de cada caso particular para aplicarlo al resto de casos desconocidos, a través de la «observación de recurrencias» (p. 411). Pura inferencia como característica de un abordaje de corte positivista debido probablemente a la influencia de la Me-

3 Un lema que, conjeturamos, podría remontarse a Juan Luis Vives, concretamente a su obra Del socorro de los pobres (1525), dividida en dos tomos: el primero dedicado al análisis del origen de la pobreza (saber) y el segundo dedicado a las diferentes propuestas de intervención frente a la pobreza ( $a c$ tuar). Cfr. Vives, 1992. 
dicina $^{4}$ a la que se encontraba estrechamente vinculada, por ejemplo, a través del doctor Cabot. De hecho, su propósito fue exponer la contribución que el Trabajo Social realizaba a la Medicina, así como la que el diagnóstico social representaba como instrumento auxiliar para esta disciplina (pp. 26 y 5 respectivamente).

Dicho de otro modo, el diagnóstico social utiliza la inferencia inductiva puesto que, a partir de algunos casos concretos, se propone plantear teorías abstractas sin tener en cuenta el método crítico. Si por medio de la observación se capta la verdad definitiva, la crítica, como elemento constitutivo del método científico, resulta prescindible desde la perspectiva epistemológica de Richmond. La crítica propia de la fase de evaluación carecía de valor para la fundadora epistemológica del Trabajo Social puesto que la observación, como fuente paradigmática exclusiva de conocimiento, propiciaba el conocimiento científico. De ahí que, dicha epistemología haya derivado en el principialismo ético que, incluso en la actualidad, prepondera en la disciplina y que se caracteriza por el cumplimiento estricto y obediente de los principios éticos del Código deontológico correspondiente. Conjeturamos que la obediencia estricta a los principios éticos a la que tendemos en el Trabajo Social, que nos lleva a no contemplar el contexto ni el sufrimiento específico del usuario, es una modalidad de la falta de actitud crítica a la que tiende a arrastrarnos el inductivismo richmoniano. Un inductivismo que bien podría ser calificado de esencialista $u$ ontologismo puesto que promueve el ajuste del usuario a la idea que tenemos de él.

El esencialismo u ontologismo preponderante en Trabajo Social se apuntala definitivamente gracias al principialismo ético que de él deriva. Ese principialismo ético que surge de la ética de Immanuel Kant y del utilitarismo consecuencialista de John Stuart Mill, consiste en la aproximación al usuario a través de la razón exclusivamente. Una razón entendida como logos apofántico griego o ajustamiento perfecto de la realidad a la idea que tengo de la misma. Por este motivo, conjeturamos que este principialismo ético es, en parte, la consecuencia ética de esta epistemología inductivista que promueve concebir al usuario como un alter ego. Este esencialismo o inductivismo epistemológico lleva a los profesionales a cumplir estricta y obedientemente con los principios éticos sin ser lo suficientemente críticos con el sufrimiento de cada usuario concreto. De ese modo es como se procede a la categorización definitiva del usuario, a la obtención de un conocimiento dogmático del mismo que, a su vez, provoca en el profesional un peligroso paternalismo intolerante y hasta violento con el usuario.

\section{El racionalismo crítico. Aproximación de la epistemología de Karl. R. Popper al Trabajo Social}

La obra de Popper se encuentra marcada por los acontecimientos ocurridos en 1919. Durante la primavera de ese mismo año se había afiliado al partido marxista. Unos meses más tarde, en una manifestación en la que los marxistas eran los instigadores, varios jóvenes socialistas murieron (Popper, 1985, pp. 45 y ss). Este hecho dejará una profunda huella en Popper, que no sólo le llevará a salirse del partido, sino a plantear una epistemología ética que apueste por el respeto al prójimo y el antidogmatismo. El conocimiento dogmático que tenemos de la realidad, sobre todo cuando a través de ella nos estamos refiriendo a un ser humano, nos puede llevar a su aniquilación. Una idea dogmática de los marxistas sobre el bando de los socialistas llevó a los primeros a justificar la muerte de aquellos obreros socialistas.

Para Popper, este dogmatismo ha adquirido diferentes apariencias a lo largo de la historia: positivismo (Popper, 1997, pp.102 y ss.), observacionismo (Popper, 1997, p. 111; Popper, 2003, p. 159) u observacionalismo (Popper, 2003, p. 159), inductivismo (Popper, 1997, p. 138), mito baconiano (Popper, 2003, p.176), expresionismo (Popper, 2010, p. 235), verificacionismo, justificacionismo, esencialismo, substancialismo, etc. Para Popper, todos ellos se caracterizan por pretender encubrir u ocultar nuestra responsabilidad para con

\footnotetext{
${ }^{4}$ Richmond, 2007: 39, 40, 73-79, 76-78, 79-81, 82, 84, 85-94, 121-122, 408-409.
} 
los demás. Debido a la adquisición de un conocimiento infalible, dogmático, perfecto, válido a priori (definitivo antes de ser sometido a crítica) y verificable (a través de enunciados observacionales), los profesionales tendemos a ejercer nuestro dominio y superioridad sobre los usuarios como expertos que se encuentran en posesión de la verdad. Este hecho nos lleva a aproximarnos al usuario como a un alter ego: tras observar al usuario a través de mis sentidos, éste pasa a ser un alter ego, una idea mía a la que lo ajusto. Así, de aquí a la justificación de los sucesos de 1919 presenciados por Popper no hay más que un paso.

El racionalismo crítico de Popper se caracteriza porque plantea un conocimiento que es científico porque es provisional, no definitivo, falible, no dogmático, objetivo (lingüísticamente formulable), no violento, no válido a priori (genéticamente a priori, pero válido a posteriori, es decir, tras someter el conocimiento a crítica) y refutable, falsable (sometible a crítica). Un conocimiento que sólo es científico porque es ético. No en vano, corroborando la tesis defendida por Artigas (2001), la epistemología de Popper es una consecuencia de tres principios éticos: el principio de falibilidad, el de discusión racional y el de aproximación a la verdad. De hecho, «los tres principios son principios teoréticos del conocimiento y al mismo tiempo éticos. Pues implican entre otras cosas tolerancia» (Popper, 1992, pp. 153-154).

Todas ellas son medidas antidogmáticas que nos instan a no volver a ejercer la violencia, la intolerancia y la crueldad como profesionales expertos frente al usuario. Medidas que expresan la máxima tolerancia «pero ninguna concesión a la intolerancia, a la violencia y a la crueldad» (Popper, 1992: 145). Intolerancia, violencia y crueldad que han sido promovidas por posturas epistemológicas dogmáticas a las que anteriormente aludíamos (esencialismo, substancialismo, expresionismo, inductivismo, etc.). De hecho, en estas perspectivas, la certeza y seguridad absolutas del conocimiento como máxima autoridad han promovido, a lo largo del tiempo, posturas paternalistas y hasta fanáticas sobre las que Popper trata de llamar la atención a los intelectuales.
Así la epistemología clásica ha dado lugar a un conocimiento del prójimo que ha tenido como consecuencia nuestra intolerancia para con él. Una intolerancia que, a lo largo de los siglos, ha conseguido perdurar implícita en los diferentes códigos de conducta moral derivados de dicha epistemología clásica. Para Popper, de la epistemología clásica ha derivado una «vieja ética profesional» a través de la cual se ha venido ejerciendo el dogmatismo de aquélla. Por todo ello, frente a esta vieja ética, Popper plantea «una nueva ética profesional» (p. 154). Para Popper la vieja ética profesional derivaba de un saber seguro, de un saber verificable que es presentado como máxima autoridad, como fundamento absoluto, incuestionable, como explicación última y definitiva de la realidad. Precisamente por ello, «esta vieja ética profesional es intolerante. $Y$ era también siempre intelectualmente desleal: conduce al encubrimiento del error a favor de la autoridad, especialmente en la medicina» (p. 155).

Efectivamente, las diferentes modalidades, adoptadas a lo largo de los siglos por la epistemología clásica, han posibilitado que profesionales tan paradigmáticos como los médicos oculten sus errores tras su apariencia de expertos poseedores de la verdad absoluta: yo sé, luego no me equivoco y por eso tengo el poder y el dominio sobre ti. Por ello, el planteamiento ético-epistemológico de Popper apunta al descentramiento de la autoridad de los profesionales en detrimento de la investidura de la primacía del usuario al que debemos respetar y capacitar como sujeto crítico $\mathrm{y}$ autocrítico. Este planteamiento significa que el profesional del Trabajo Social debe ser autocrítico con su intervención social, crítico con sus usuarios, a la par que promueve la capacitación del usuario, mostrándole la importancia de la actitud crítica y autocrítica frente a su vida y sus circunstancias.

Siguiendo los principios ético-epistemológicos de Popper, resulta inevitable que cometamos errores, aunque debemos intentar que sean los menos posibles. Por ello, es nuestra obligación respetar tal falibilidad en los demás, en el usuario al que no impondremos nuestro criterio y al que instaremos a que tome sus propias decisiones de forma crítica y autocrítica. Todo esto se llevará a ca- 
bo a través de la discusión racional que tiene como premisa el lema que concentra la propuesta ético-epistemológica de Popper: «yo puedo estar equivocado y tú puedes tener razón y, con un esfuerzo, podemos acercarnos los dos a la verdad $\rangle^{5}$. Dicho de otro modo, este «credo moral» de Popper consiste en el reconocimiento por nuestra parte de que podemos equivocarnos y de que el prójimo, sea el usuario o el colega, puede tener la razón. Por ello, propone Popper, dispongámonos a hacer concesiones mutuas (2002, p. $137 ; 2010$, p. 181) para que ambos podamos aprender y descubrir nuestros errores a través de la crítica recíproca, como único modo de poder mejorar y progresar.

De este modo, el conocimiento que adquirimos del usuario será provisional, falible y refutable, lo cual provoca en el profesional una actitud siempre respetuosa de quien habla de igual a igual y no de experto a sujeto ignorante e inmaduro (como sucediera en la vieja ética). Una actitud respetuosa para con el usuario del que adquirirá un conocimiento que siempre será mejorable debido a que el profesional aspira a la verdad como idea regulativa inalcanzable $(2010$, p. $283 ; 2002$, p. $36 ; 1997$, p. 199). Esta verdad la entiende Popper como correspondencia del enunciado con los hechos 6 . De este modo, nunca podremos estar seguros de la verdad o falsedad de nuestras teorías porque no existen criterios de verdad, de verificabilidad que nos lo puedan corroborar: aunque estemos ante la verdad no lo podremos saber ${ }^{7}$.

Así, el conocimiento hipotético, conjetural, que adquirimos del usuario, que se caracteriza por encontrarse sometido a crítica, nos lleva a una actitud respetuosa, tolerante y responsable para con él y a reconocerle como «mi igual en potencia» (1992, p. 154). El mismo método crítico por el que, según Popper, se caracteriza el método de la ciencia, no sólo es el núcleo central de su epistemología, sino también de su ética, dado que impide la categorización definitiva del usuario, al que nos aproximamos a través de teorías siempre pro- visionales, refutables y perfectibles. El método crítico, es decir, el método de ensayo y la eliminación del error (2010, p. 33), impide la instrumentalización de las teorías (1997, p. 215; 2003, p. 135), así como la reducción de dicho método a simple instrumento (1997, p. $215 ; 2003$, pp. 135, 146, 148), de modo que pasemos a contemplarlo como una actitud crítica frente a la realidad. Dicho instrumentalismo es una forma de esencialismo debido a que concibe que la realidad, siempre observable, se ajusta perfectamente a la teoría que tengamos de la misma (Popper, 2003, p. 139), a través de reglas de inferencia (p. 146) que prescinden del método crítico (p. 148). Este esencialismo que adopta la forma de inductivismo es el mismo sobre el que Richmond sustentaba las bases epistemológicas del Trabajo Social. Un inductivismo del que derivaba otra versión de la vieja ética profesional a la que nos referiremos como principialismo ético.

Frente al inductivismo epistemológico del Trabajo Social, Popper plantea partir de hipótesis, conjeturas o teorías tentativas. Cualquier fuente de conocimiento es válida mientras se encuentre sometida a crítica y sea rigurosamente testada. El conocimiento hipotético que plantea Popper distingue entre conocimiento subjetivo y objetivo. De hecho, el conocimiento objetivo es aquel lingüísticamente formulable, perteneciente al mundo 3 $\mathrm{y}$ aquel que puede prescindir de sujeto cognoscente $(2010$, p. $137 ; 1997$, p. 188). Este conocimiento hipotético es falible, no dogmático ni valido a priori y es refutable. De ahí que sea un conocimiento científico que instaure el respeto al usuario, siendo por ello mismo un conocimiento ético. El usuario no es una de las ideas del profesional y por ello su objeto de dominio, sino que es aquel sujeto que, del mismo modo que el profesional, es falible, es capaz de discutir racionalmente $\mathrm{y}$, para solucionar su problemática, pretende, con los medios a su alcance, aproximarse a la verdad. En definitiva, el conocimiento científico (provisional, hipotético, perfectible, re-

5 Cfr. Popper, 1982: 393, 404, 405; Popper, 2002: 137-138; Popper, 1997: 13; 2003: 426.

${ }^{6}$ Cfr. Popper, 2010, pp. 149 (9), 378; Popper, 1997, p. 216; Popper, 2003, pp. 273, 275; Popper, 1992, p. 148.

7 Cfr. Popper, 2010, pp. 350-351; Popper, 1997, pp. 217, 250; Popper, 2003, p. 77; Popper, 1992 , p. 149. 
futable, etc.) instaura la tolerancia y la responsabilidad del profesional para con el usuario. Y es así, como ya anticipábamos, porque para Popper la epistemología supone la ética, tras su fatídica y tormentosa experiencia vital de 1919.

La epistemología popperiana es consecuencia de la ética. Dicho de otro modo, hemos de evitar que el conocimiento adquirido nos lleve a ejercer la intolerancia, la violencia y la crueldad. Por esta razón, el método científico, es decir, el método crítico, es a la vez epistemológico y ético. De hecho, no puede ser epistemológico si no es ético y viceversa. La ética es inherente al conocimiento científico propuesto por Popper y al que llegamos a través de la actitud crítica sistemática, constante y consciente. Esta crítica es la que instaura, por tanto, un conocimiento científico y ético. Un conocimiento que dista considerablemente del que propusiera Richmond como base epistemológica del Trabajo Social que era pseudocientífico y tendente al dogmático. La actitud crítica del profesional es la que hace del Trabajo Social una disciplina tanto científica como ética. Esta es la primera de nuestras propuestas para el Trabajo Social inspirándonos en la aportación del racionalismo crítico de Popper.

\section{5. Ética del rostro. Aproximación de la éti- ca de E. Lévinas al Trabajo Social}

La obra del filósofo judío Emmanuel Lévinas, del mismo modo que la de Karl Popper, se encuentra profundamente marcada por su experiencia vital. El ascenso de Hitler al poder, la afiliación de Martin Heidegger al partido nacionalsocialista y su experiencia como prisionero en un campo de trabajo nazi, dejaron una huella imborrable en Lévinas. El aniquilamiento de sus familiares más cercanos a manos de las tropas nazis, así como el indiferente e inhumano tratamiento del ejército nazi a los prisioneros judíos en los campos de exterminio pudieron ser los acontecimientos vitales sobre los que nunca hablará, pero que le impulsaron a elaborar una propuesta ética del más alto nivel. Quizás, tras presenciar el masivo aniquilamiento de los judíos, por ello también sea tan repetida en sus obras la expresión reducción del Otro a lo Mismo, es decir, el ajuste del prójimo a la idea que tengo de él, hasta hacerlo un objeto de mi dominio apropiativo.

Los campos de exterminio nazi pudieron ser materia prima que inspirara dolorosamente a Lévinas en su propuesta ética. Decimos dolorosamente porque concibe la ética como sufrir por el sufrimiento del Otro y, por ello, como patética. Para Lévinas, la vulnerabilidad del Otro despierta la mía propia a modo de respuesta prevoluntaria a él. Esta vulnerabilidad es trasladada irreductiblemente al rostro del Otro. Por la ontologización de la epistemología tendemos a contemplar al Otro como alter ego, como idea nuestra. Intelectualizamos nuestro acercamiento al Otro: lo abordamos racionalmente, lo que impide que lleguemos a sentir con él ese sufrimiento que lo hace único. En este factor ha tenido mucho que ver el ontologismo que tan radical y valientemente denuncia Lévinas. Tener este ontologismo como trasfondo epistemológico es lo que, según este autor, ha llevado a que lleguemos a reducir al Otro a lo Mismo.

A continuación, explicaremos algunas nociones principales que Lévinas maneja en las que consideramos son sus obras más importantes: Totalidad e Infinito (1961) y De otro modo que ser o más allá de la esencia (1976). Nociones a la luz de las cuales plantearemos su propuesta ética. De entre las diferentes nociones que maneja, consideramos fundamentales el rostro del Otro y la responsabilidad. El rostro lo entendemos como aquella vulnerabilidad del Otro que despierta la mía propia a modo de respuesta prevoluntaria a él. Es por ello por lo que la responsabilidad la entendemos como ofrecimiento prevoluntario al Otro, como voluntad investida por la sensibilidad o como bondad que precede a la libertad. En palabras de Lévinas, ésta es «una responsabilidad que desborda la libertad» (2006b, p. 102), que nos lleva más allá del ser, como deseo irrefrenable de ayudar al Otro. Así, el Otro, pese a ser inalcanzable por hallarse en las coordenadas

${ }^{8}$ Entendida como tiempo imprevisible del Otro que siempre me precede. Tiempo de lo contingente que no puedo anticipar y que, por ello, siempre se me escapa. 
espacio-temporales de la diacronía ${ }^{8}$ y de lo más allá del ser ${ }^{9}$, provoca mi sensibilidad y mi vigilancia.

La sensibilidad es una noción que comienza a desarrollar Lévinas a partir de Totalidad e Infinito (2006b, pp. 201-207), aunque más específica y profundamente en De otro modo que ser o más allá de la esencia (2003, pp. 5960,117-162), mientras que las primeras huellas del término vigilancia las encontramos, a nuestro modo de ver, en sus primeras obras, cuando se refiere al insomnio (2000, pp. 10 y ss ). Según reconoce el autor: "yo he descrito la responsabilidad ética como insomnio o un mantenerse despierto, alerta precisamente porque implica un perpetuo deber de vigilar (...). El amor representa un incesante velar por el interés del otro» (Lévinas y Kearney, 1998, p. 214). Una sensibilidad (2003) que -entendemos-consiste en la apertura prevoluntaria como expresión de mi vulnerabilidad tras la crítica, el juicio, la irrupción del rostro del Otro. $\mathrm{Y}$ una vigilancia (op. cit.), entendida como autocrítica exigida por esta sensibilidad que me lleva a descategorizar al Otro.

A la luz de tales nociones, pasamos a exponer la propuesta ética de Lévinas. Para este autor, el humanismo clásico se caracteriza porque la aproximación al Otro se realiza exclusivamente por la razón, porque se tiende a categorizar definitivamente al Otro, así como porque el sujeto ético tiende a intelectualizar los aspectos emocionales del Otro. Frente a esta perspectiva, Lévinas propone el humanismo del Otro, que fundamenta en nociones anteriormente señaladas como la sensibilidad y la vigilancia. Entendemos que la sensibilidad es una noción que tiene origen hebreo y que privilegia la conmoción de entrañas ${ }^{10}$, así como la vulnerabilidad, la irreductibilidad y la primacía del Otro. Para Lévinas, «todo amor o todo odio del prójimo como actitud, refleja, supone una vulnerabilidad previa: misericordia, "conmoción de entrañas". Desde la sensibilidad, el sujeto es para el Otro: sus- titución, responsabilidad, expiación» (2006a, p. 125).

Por otra parte, consideramos que la noción de vigilancia tiene tanto origen hebreo como griego. Tiene, en parte, origen hebreo puesto que privilegia la autocrítica que me lleva a la descategorización del Otro, siempre irreductible. Una autocrítica exigida por la sensibilidad preoriginaria que la inviste. Tiene, en parte, también origen griego porque -consideramos-que dicha noción de vigilancia toma probablemente como referente la epojé husserliana (2003, pp. 59, 96, 124-125, 130, 246), es decir, el método fenomenológico utilizado por Lévinas desde sus inicios, que nunca abandonará, consiste en remontar lo tematizado a su estado anterior. Actitud que consiste en criticar el prejuicio o autocriticar nuestras propias intervenciones y que -como anticipábamos-comienza adquiriendo la forma y las características del insomnio en sus primeras obras. Así, el hecho de que la conciencia sea exigida a mantenerse vigilante, a diferencia de aquélla que no lo es. No en vano, la conciencia ética, es decir, aquella vigilancia investida por la sensibilidad, vela por descategorizar al Otro tras la categorización, mientras que la conciencia ontológica, «como fijo estado de cosas que es» (1998, p. 214), no lo considera necesario, llegando así a reducir lo Otro a lo Mismo, es decir, a categorizarlo definitivamente.

Por todo ello, la propuesta ética de Lévinas aboga precisamente por ir siempre más allá del cumplimiento estricto de tales principios éticos, siendo críticos con el sufrimiento de cada caso concreto, así como autocríticos con nuestra propia intervención. Crítica y autocrítica que se traducen en términos levinasianos como vigilancia investida por la sensibilidad preoriginaria a la que somos despertados por el rostro del usuario. Si para Lévinas la ontología se encuentra investida por la ética, el principialismo ético u ontologismo deberá encontrarse, siguien-

${ }^{9}$ Locus correspondiente a la temporalidad diacrónica. No-lugar que impide la fenomenalización totalitaria o categorización definitiva por parte del sujeto que recibe al Otro. Zona inexplorable y no conceptualizable por inalcanzable a la conciencia cognitiva del sujeto.

10 Expresión bíblica (Cfr. Jr 30,21) que Lévinas interpreta como afectación corpórea diacrónica no cognitivamente categorizable, no intelectualizable, es decir, irreductible al saber de la conciencia cognitiva (Lévinas, 2003, pp. 59, 79, 109, 119, 121, 205, etc.). 
do a este autor, al auspicio de la ética en el Trabajo Social. Las operaciones ontológicas deberán estar vigiladas por el profesional para impedir categorizar definitivamente al usuario.

Llegados a este punto, nos centraremos a continuación en la aproximación de la ética de Lévinas al Trabajo Social. Una aproximación que realizaremos confrontando el lema inductivista de Richmond saber para actuar (Miranda, 2004, p. 205), con el de Lévinas, actuar antes que todo saber (2003, pp. 56, $213,226,260)$. Así, en la propuesta de Richmond, la ética se encuentra ontologizada y consiste en el cumplimiento estricto y obediente de los principios éticos por parte del sujeto ético. En la ética ontologizada se generaliza, es decir, se pasa de lo concreto a lo abstracto, debido al método inductivo. Es una ética en la que se tiende a categorizar definitivamente al usuario. Es decir, si lo observado a través de los sentidos es la verdad última, definitiva e incuestionable, el usuario pasa a ser un alter ego, una idea mía a la que lo ajusto. En definitiva, el sujeto ético cumple estricta y obedientemente con los principios éticos sin ser lo suficientemente crítico con el sufrimiento de cada caso concreto, la aproximación al usuario se realiza por la razón exclusivamente, se tiende a categorizar definitivamente al usuario y la última palabra la tiene el profesional, que intelectualiza los aspectos emocionales del usuario.

Inspirados en la propuesta de Lévinas, la ontología se encuentra al auspicio de la ética en el Trabajo Social que proponemos. De este modo, el sujeto ético consigue ir siempre más allá del cumplimiento estricto y obediente de los principios éticos, siendo crítico con el sufrimiento de cada caso concreto. No se generaliza, sino que se personaliza, teniendo en cuenta el sufrimiento del usuario así como el contexto específico en el que éste se origina. Es decir, se pasa de lo abstracto y general de los principios éticos al caso concreto del usuario y, gracias al saber ético, conseguimos descategorizarlo tras cada categorización. En esta propuesta, la aproximación al usuario se realiza por la sensibilidad, tras la categorización se procede a la descategorización del usuario y pese a que la última palabra la siga teniendo el profesional, éste es capaz de cap- tar los aspectos emocionales del usuario sin categorizarlo definitivamente.

\section{Conclusiones}

Finalmente, señalaremos las conclusiones a las que hemos llegado. A la hora de plantearlas seguiremos el orden expositivo desarrollado, explicando primero las relativas a la aproximación de la propuesta de Popper al Trabajo Social y, a continuación, las conclusiones relativas a la aproximación de la propuesta de Lévinas al Trabajo Social. Los disturbios presenciados por Popper, poco antes de cumplir los diecisiete años, pudieron llevarle a plantear una epistemología ética. Tras este suceso, Popper comprendió que las ideas pueden matar, lo que le llevó a proponer el método crítico como método ético-científico. La epistemología clásica, que, entre otras apariencias, adopta la forma del inductivismo, da lugar a un conocimiento dogmático, violento y cruel. Una epistemología de la que se deriva la vieja ética profesional que se sustenta sobre el conocimiento seguro, infalible e intolerante del profesional, que lo ejerce de modo paternalista, como autoridad superior frente al usuario. Por ello, la propuesta de Popper es una nueva ética profesional que sintetiza en doce puntos que pasamos a señalar a continuación aproximándola al Trabajo Social.

Dado que el saber es conjetural, no puede haber autoridad alguna por parte del profesional del Trabajo Social. Somos falibles y la perfección no existe más que como aspiración. Las/los trabajadoras/es sociales debemos intentar no cometer errores, siendo conscientes de lo complicado que resulta evitarlos. Por ello, la búsqueda de errores debe ser tarea específica del profesional del Trabajo Social como científico. El descubrimiento de los mismos es lo que nos lleva a modificar nuestro dogmatismo inicial, contraído por el cumplimiento de la vieja ética profesional encubridora de errores. Las/los trabajadoras/es sociales hemos de aprender de nuestros errores y no debemos autoengañarnos, ocultándolos o encubriéndolos: hemos de hallar las causas de los mismos.

Por todo lo anteriormente expuesto, la crítica y la sinceridad se nos imponen como un deber profesional: debemos reconocer nues- 
tros errores y agradecer a los demás que nos los trasladen, de modo que, cuando nos toque realizar la crítica a nuestro colegas, caigamos en la cuenta de que nosotros también cometemos errores muy parecidos. En consecuencia, necesitamos a los demás (usuarios, colegas, instituciones, etc.) para aprender de nuestros errores, ser tolerantes y ser tan críticos como autocríticos con nosotros mismos. De hecho, la autocrítica surge de la crítica de los demás. Finalmente, la crítica efectuada por los profesionales del Trabajo Social debe guiarse por la idea de aproximación a la verdad objetiva. Es decir, la consecuencia de la crítica es un conocimiento hipotético que, siendo el que más se acerca a la verdad, reconoce que puede ser nuevamente refutado por otro que se acerque en un futuro todavía más a la verdad (Popper, 1992, pp. 156-158).

Por ello, inspirados en la nueva ética profesional propuesta por Popper, planteamos que la actitud crítica y autocrítica del profesional en Trabajo Social es una actitud éticoepistemológica falibilista (principio de falibilidad), antidogmática y no violenta, que impide la categorización definitiva del usuario (principio de aproximación a la verdad) y que nos lleva a respetarlo, a ser tolerantes y responsables con él, capacitándolo a través de la discusión crítica (principio de discusión racional) para que también él se mantenga crítico y autocrítico consigo mismo y con los demás.

La experiencia de Lévinas como prisionero en un campo de trabajo nazi también influyó decisivamente en su obra. Para Lévinas la ética nos impulsa a ir siempre más allá del ser, entendiéndola por ello como metafísica. Una ética que consiste en padecer por el sufrimiento del Otro, siendo por ello considerada por Lévinas como patética. Tanto el rostro como la responsabilidad son nociones transversales de toda su obra. Así, tener la ética como primera filosofía consiste en mantener irreductible la singularidad del Otro. Algo que se logra a través de la vigilancia exigida por la sensibilidad, que consiste en que tras la categorización del Otro, el sujeto ético es exigido a descategorizarlo, debido a que le vuelve a mirar nuevamente al rostro.

A nuestro modo de ver, la ética se encuentra ontologizada en el Trabajo Social debido a que se fundamenta en el principialismo ético que surge del utilitarismo y de la ética kantiana y que consiste en la aproximación al usuario por la razón exclusivamente. Es lo que hemos podido comprobar en la propuesta de Richmond cuyo lema, saber para actuar, se concentra en su diagnóstico social. Richmond utiliza el método inductivo por el que tiende a categorizar definitivamente al usuario, así como a relegar el Bien a la Verdad. Un método inductivo que no incrementa el conocimiento (debido a que consideramos que sin crítica no hay progreso científico) y que se enfrenta al Trilema de Müchhausen: regreso infinito, circularidad lógica, dogmatismo (Ursúa, 1993, p. 48). Desde este punto de vista, la propuesta de Jane Addams, cuyo lema fuera actuar para saber, es la propuesta de Trabajo Social que más coincide con la ética de Lévinas, debido al saber provisional que postula, cercano al saber ético del filósofo judío (Idareta, 2010a), aunque también al conocimiento hipotético o conjetural propuesto por el filósofo austríaco.

Finalmente señalaremos que la aproximación de la ética de Lévinas al Trabajo Social la hemos efectuado a través de las nociones de sensibilidad, entendida como actuar antes que todo saber, y de vigilancia, entendida como atención a la descategorización del usuario. De este modo, la vigilancia exigida por la sensibilidad nos lleva siempre a ir más allá del ser. Ir más allá del ser que consiste en que, partiendo de los principios éticos, los personalizamos en el caso concreto del usuario, velando por descategorizarlo tras la categorización diagnóstica. Es decir, ayudamos al usuario a ayudarse a sí mismo sin categorizarlo definitivamente, protegiendo de ese modo su decisión autónoma.

Ir más allá del ser no deslegitima al profesional mientras éste tenga la ética como primera filosofía, dado que así es como se encuentra sometido tanto a la crítica (del rostro del usuario, del rostro de sus colegas, etc.), como a la autocrítica (por medio de su propia vigilancia). En definitiva, ir más allá del ser establece la primacía del usuario, tendencia contraria al paternalismo, que supone para el profesional, por una parte, acoger racionalmente sus aspectos emocionales sin categorizarlo definitivamente y por otra, un plus de 
responsabilidad. En el primer caso, en un principio, se siente al usuario, seguidamente, se sabe o se categoriza al usuario, para, finalmente, descategorizarlo. Así, gracias a sentir prevoluntariamente la irreductibilidad de la singularidad del usuario, somos capaces de descategorizarlo. Es decir, no lo categorizamos definitivamente al volver a mirarle nuevamente al rostro irreductible. En el segundo caso, el plus de responsabilidad consiste en someter a crítica constante nuestra intervención en todo momento.

En definitiva, ir más allá del ser consiste en tener la ética como primera filosofía en el Trabajo Social. Gracias a tener la ética como primera filosofía, el/la profesional del Trabajo Social es capaz de ir más allá del ser, más allá del cumplimiento estricto y obediente de los principios éticos. De hecho, entendemos que ir más allá del ser consiste en que, partiendo de tales principios, el profesional, gracias a la sensibilidad a la que ha sido despertado por el rostro del usuario, no sólo los personaliza en cada caso concreto sin categorizarlo definitivamente, protegiendo así su elección autónoma; sino que el profesional, gracias a esta sensibilidad, siente en adelante la exigencia de mantener una actitud crítica $-y$ por ello vigilante- con el sufrimiento de cada usuario, así como una actitud autocrítica constante para con su propia intervención. Por ello nuestra propuesta pretende ser un complemento que amplía el alcance del principialismo ético imperante en el Trabajo Social gracias a las nociones de sensibilidad y vigilancia propuestas por Lévinas.

Tras haber analizado los puntos que hemos considerado más relevantes de las propuestas de ambos autores, hemos de concluir que, pese a sus divergencias, seguimos considerando que podrían coincidir en el trasfondo de sus propuestas. Ya que para ambos autores la epistemología u ontología supone o inviste la ética. La propuesta de ambos autores gira en torno a la ética. De hecho, sin la ética, sus propuestas carecerían de todo el sentido. El conocimiento científico no puede serlo sin que sea ético, sin que sea respetuoso con el Otro, con el prójimo, con el usuario. Popper es el que ha planteado en qué consiste el conocimiento científico de modo mucho más elaborado que Lévinas, mientras que Lévinas es el que más ha desarrollado los efectos de un conocimiento ontológico $\mathrm{y}$, según él, dogmático sobre el Otro. Por lo tanto, conjeturamos que sus propuestas no sólo son complementarias la una de la otra, sino que consiguen dar conjuntamente respuesta a la necesidad de conocimiento ético-científico que urge en el actual Trabajo Social. La actitud crítica, propuesta de modo diferente desde sus diferentes perspectivas, resulta ser, desde nuestro punto de vista, la clave que hará del Trabajo Social una disciplina ético-científica. Esta es nuestra aportación al Trabajo Social inspirados en las propuestas de Popper y Lévinas.

\section{Referencias bibliográficas}

Artigas, M. (1979). K.R. Popper. Búsqueda sin término. Madrid: Magisterio Español.

Artigas, M. (2001). Lógica y ética en Karl Popper. Pamplona: Eunsa.

Fernández, T. y López, A. (2008). Trabajo Social con Grupos. Madrid: Alianza.

Fernández, T. y Ponce, L. (2008). Naturaleza, filosofía, valores y principios del Trabajo Social con Casos. En T. Fernández (coord.). Trabajo Social con Casos (pp. 33-58). Madrid: Alianza.

Idareta, F. (2010a). Desde la Compasión de J. Addams a la Responsabilidad para con el Otro: La propuesta ética de E. Lévinas para el Trabajo Social. Portularia, 10(2), 65-75.

Idareta, F. (2010b). Ética como primera filosofía: aproximación de la ética de E. Lévinas al Trabajo Social. (Tesis doctoral inédita), Universidad Pública de Navarra.

Lévinas, E. y Kearney, R. (1998). Ética del Infinito. En R. Kearney. La paradoja europea (pp. 197-218). Barcelona: Tusquets.

Lévinas, E. (2000). De la existencia al existente. Madrid: Arena.

Lévinas, E. (2003). De otro modo que ser o más allá de la esencia. Salamanca: Sígueme.

Lévinas, E. (2006a). Humanismo del otro hombre. Madrid: Siglo XXI.

Lévinas, E. (2006b). Totalidad e Infinito: ensayo sobre la exterioridad. Salamanca: Sígueme. 
López, A. (2010). Teoría del Trabajo Social con Grupos. Madrid: Universitas.

Moix, M. (2006). Teoría del Trabajo Social. Madrid: Síntesis.

Ponce, L. y Fernández, T. (2009). El conocimiento científico y las bases metodológicas del Trabajo Social. En T. Fernández. Fundamentos del Trabajo Social (pp. 249-291). Madrid: Alianza.

Popper, K. R. (1982). La sociedad abierta y sus enemigos. Barcelona: Paidós.

Popper, K. R. (1985). Búsqueda sin término. Una autobiografía intelectual. Madrid: Tecnos.

Popper, K. R. (1990). La lógica de la investigación cientifica. Madrid: Tecnos.

Popper, K. R. (1992). Sociedad abierta. Universo abierto. Madrid: Tecnos.

Popper, K. R. (1994). En busca de un mundo mejor. Madrid: Tecnos.

Popper, K. R. (1997). El mito del marco común. En defensa de la ciencia y la racionalidad. Barcelona: Paidós.

Popper, K. R. (2002). La responsabilidad de vivir. Escritos sobre política, historia y conocimiento. Barcelona: Paidós.

Popper, K. R. (2003). Conjeturas y refutaciones. El desarrollo del conocimiento científico. Barcelona: Paidós.

Popper, K. R. (2010). Conocimiento objetivo. Madrid: Tecnos.

Richmond, M. (1977). Caso Social Individual. Buenos Aires: Humanitas.

Richmond, M. (2007). Diagnóstico Social. Madrid: Siglo XXI.

Soydan, H. (2004). La historia de las ideas en el Trabajo Social. Valencia: Tirant Lo Blanch. Ursúa, N. (1993). Cerebro y conocimiento: un enfoque evolucionista. Barcelona: Anthropos.

Vázquez, O. (2008). Los instrumentos de evaluación. En T. Fernández (coord.). Trabajo Social con Casos (pp. 221-250). Madrid: Alianza.

Viscarret, J. J. (2007). Modelos y métodos de intervención en Trabajo Social. Madrid: Alianza. Vives, J. L. (1992). Del socorro de los pobres. Madrid: Hacer. 